\title{
Bare Metal Stent
}

National Cancer Institute

\section{Source}

National Cancer Institute. Bare Metal Stent. NCI Thesaurus. Code C80464.

A vascular metal mesh tube without a coating. 